\title{
Complications of cardiac catheterization in children with congenital heart disease
}

\author{
Kürşat Tokel ${ }^{1}$, Ayten Gümüşs ${ }^{1}$, Canan Ayabakan², Birgül Varan ${ }^{1}$, İlkay Erdoğan ${ }^{1}$ \\ Departments of Pediatric Cardiology, ${ }^{1}$ Baskent University Ankara Hospital, Ankara and ${ }^{2}$ Başkent University Istanbul \\ Health and Training Hospital, İstanbul, Turkey. E-mail: cayabakan@yahoo.com \\ Received: 17th November 2017, Revised: 12th December 2017, 3rd January 2018, Accepted: 11th January
} 2018

SUMMARY: Tokel K, Gümüş A, Ayabakan C, Varan B, Erdoğan İ. Complications of cardiac catheterization in children with congenital heart disease. Turk J Pediatr 2018; 60: 675-683.

Catheterization procedures for congenital heart disease include a broad range of procedures with a large spectrum of potential adverse outcomes. We aimed to determine the incidence of various complications during pediatric cardiac catheterizations and to designate the relative risk factors for such complications.

All pediatric patients undergoing cardiac catheterizations between January 2005-December 2010 were included. Data are collected prospectively by filling out computerized catheterization reports. Patient records were scanned for potential risk factors retrospectively. Groups were divided based on cardiac diagnosis; type of procedure. Adverse events were categorized into major or minor events. A total of 2662 cardiac catheterizations were performed during this period. The mean age of patients was 53.2 \pm 64.3 months. Diagnostic catheterizations were done for 1797 (67.5\%) patients, and interventional procedures were done in $865(32.5 \%)$ cases. Adverse events were observed in 688 patients $(26 \%)$ during 941 procedures. Minor and major events were seen in $21.4 \%$ and $7.1 \%$ of the procedures respectively. Most frequent major complications were anesthesia related (6\%), most frequent minor complications were vascular complications $(\mathbf{4 5 . 2 \% )}$ ). Complications were more frequent in younger patients $(p=0.0001)$, during interventional procedures $(p=0.0001)$. Thirteen patients died after a cardiac catheterization; they were younger and had longer procedures compared to those who survived $(p=0.0001)$. Vascular complications were frequent among younger patients, with prolonged procedure time and vessel access $(\mathrm{p}<0.0001)$. Cyanotic patients had more complications $(\mathrm{p}<0.05$; OR for major and minor complications: 3.5 and 2 respectively). Minor complications were 2.7 times more likely in ventricular outflow obstructions $(\mathrm{p}<0.05)$.

The complication rates of cardiac catheterization in children are low, but not negligible. Defining risk factors will help anticipate adverse events, which will guide in preparation for rescue procedures and improvement of patient safety systems in catheterization laboratories.

Key words: pediatric, catheterization, complications.

The role of pediatric cardiac catheterization has changed dramatically over the last two decades and it has become a common therapeutic interventional tool in the current era. Both interventional and diagnostic procedures are associated with some risk because of the invasive nature of the procedures. ${ }^{1}$ Catheterization procedures for congenital heart disease include a broad range of procedures with a large spectrum of potential adverse outcomes. ${ }^{2}$ The aim of this study was to determine the incidence of various complications during pediatric congenital cardiac catheterizations and to designate the relative risk factors for such complications. 


\section{Material and Methods}

All patients undergoing diagnostic or interventional pediatric cardiac catheterizations between January 2005 and December 2010 at our institution were included. An adverse event was defined as any event for which injury occurred or could have occurred, potentially or definitely as a cause of catheterization procedure. Informed consent was obtained from the parents of all individual participants included in the study.

This study was evaluated by "the Medical and
Health Sciences Research Committee" and "Medical Ethics Committee" of our institution. It was approved and assigned as a research project with a registration number of KA11/51. All procedures performed were in accordance with the 1964 Helsinki declaration and its later amendments or comparable ethical standards.

Data were collected prospectively. In every case, the pediatric cardiologist performing the procedure was required to fill out a computerized catheterization report about the details of the procedure focusing on the

Table I. Potential Risk Factors for Adverse Outcome in Pediatric Cardiac Catheterization Procedures.

\begin{tabular}{|c|c|}
\hline Demographic data & $\begin{array}{l}\text { Age } \\
\text { - Newborn (1-30days) } \\
\text { - Infant (1 month-1 year) } \\
\text { - Child (1-12 years) } \\
\text { - Adolescent (12-21 years) }\end{array}$ \\
\hline \multirow{6}{*}{ Cardiac diagnosis } & Body weight \\
\hline & $\begin{array}{l}\text { Left-to right shunt } \\
\text { - Preoperative } \\
\text { - Palliation/residual } \\
\text { - Total correction }\end{array}$ \\
\hline & $\begin{array}{l}\text { Cyanotic } \\
\text { - Preoperative } \\
\text { - Palliation/residual } \\
\text { - Fontan operation } \\
\text { - Total correction }\end{array}$ \\
\hline & Outflow obstructions* \\
\hline & Cardiomyopathies \\
\hline & Cardiac transplantation \\
\hline \multirow[t]{7}{*}{ Procedural details } & Time taken to vascular access \\
\hline & Procedure time \\
\hline & $\begin{array}{l}\text { Vascular access } \\
\text { - Venous } \\
\text { - Arterial }\end{array}$ \\
\hline & $\begin{array}{l}\text { Procedure type } \\
\text { - Diagnostic } \\
\text { - Interventional }\end{array}$ \\
\hline & Fluoroscopy time \\
\hline & Amount of contrast used \\
\hline & $\begin{array}{l}\text { Hemoglobin } \\
\text { - Preprocedural } \\
\text { - Postprocedural }\end{array}$ \\
\hline \multirow[t]{3}{*}{ Anesthesia/sedation details } & General anesthesia/Conscious sedation \\
\hline & Endotracheal intubation \\
\hline & Inotropic drug infusion \\
\hline
\end{tabular}

*Obstructive lesions are; aortic stenosis, pulmonary stenosis, coarctation of aorta. 
complications. The patients were observed throughout the period of admission; those occurring after the procedure were added at the time of identification. All catheterization records and computerized patient records were scanned thoroughly for potential risk factors (given in Table I) retrospectively. If more than one complication was observed, both events were considered separately.
The patients were divided into groups based on their diagnoses (Table I). The procedures were categorized as diagnostic or interventional. Severity of complications was designated as minor or major complications. In addition, adverse events were categorized into: cardiac events (ie, cardiac arrest, myocardial ischemia, cyanotic spell, decompensation requiring inotropic support), arrhythmias, vascular complications (ie, bleeding, occlusion), catheter

Table II. Classification of Complications.

\begin{tabular}{|c|c|c|}
\hline Major Complications & & Minor Complications \\
\hline \multicolumn{3}{|l|}{ Death } \\
\hline \multirow[t]{6}{*}{ Cardiac } & Myocardial ischemia & \\
\hline & Inotropic support & \\
\hline & Hypoxic spell & \\
\hline & Cardiac arrest & \\
\hline & Transfer to ICU & \\
\hline & Emergent surgery & \\
\hline Arrhythmia & $\begin{array}{l}\text { Requiring DC cardioversion, } \\
\text { defibrillation, PM, antiarrhythmic } \\
\text { drugs }\end{array}$ & $\begin{array}{l}\text { Transient and not requiring medication or } \\
\text { intervention }\end{array}$ \\
\hline \multirow[t]{6}{*}{ Vascular complications } & Prolonged ischemia/occlusion & Transient ischemia/occlusion \\
\hline & Pseudoaneurism & $\begin{array}{l}\text { Spontaneous recovery or after heparin } \\
\text { streptokinase or TPA }\end{array}$ \\
\hline & a-v fistula & \\
\hline & $\begin{array}{l}\text { Any complication requiring } \\
\text { surgery }\end{array}$ & \\
\hline & Bleeding requiring transfusion & Bleeding not requiring transfusion \\
\hline & Retroperitoneal intrapsoas bleeding & \\
\hline \multirow[t]{3}{*}{ Catheter intervention related } & Vessel injury/ perforation & Inability to advance sheaths, catheters \\
\hline & Cardiac injury/ perforation & \\
\hline & $\begin{array}{l}\text { Device embolization, dislodgement, } \\
\text { deformation, breaking }\end{array}$ & Device, sheath, catheter deformation \\
\hline \multirow{4}{*}{$\begin{array}{l}\text { Anesthesia and airway management } \\
\text { related }\end{array}$} & Apnea + bradycardia* & Transient desaturation** \\
\hline & Bronchospasm* & Transient apnea** \\
\hline & Desaturation* & \\
\hline & Atelectasis* & \\
\hline \multirow[t]{3}{*}{ Infections } & Sepsis & Local infections \\
\hline & Pneumonia & \\
\hline & Necrotizing Enterocolitis & \\
\hline \multirow[t]{4}{*}{ Allergic / other reactions } & Anaphylaxis & Urticaria \\
\hline & Major pyrogenic reaction $\left(>39^{\circ} \mathrm{C}\right)$ & Minor pyrogenic reaction $\left(37.8-38.9^{\circ} \mathrm{C}\right)$ \\
\hline & Prolonged hypothermia & Transient hypothermia \\
\hline & Convulsions & Methemoglobinemia \\
\hline
\end{tabular}

*leading to intubation or positive airway respiration (bag+mask); ${ }^{* *}$ recovery with nasal oxygen $\mathrm{a}-\mathrm{v}$ : arteriovenous, DC: direct current, ICU: intensive care unit, PM: pacemaker, TPA: tissue plasminogen activator 
Table III. Adverse Events Seen during Interventional Procedures.

\begin{tabular}{|c|c|c|c|c|c|}
\hline \multicolumn{2}{|c|}{ Interventional Procedure } & \multirow{2}{*}{$\begin{array}{l}\text { N (\%) } \\
175(20.2)\end{array}$} & \multirow{2}{*}{$\begin{array}{l}\begin{array}{l}\text { All } \\
\text { Complications }\end{array} \\
122(36.6)\end{array}$} & \multirow{2}{*}{$\begin{array}{l}\begin{array}{l}\text { Major } \\
\text { Complications }\end{array} \\
29(8.7)\end{array}$} & \multirow{2}{*}{$\begin{array}{l}\text { Minor } \\
\text { Complications } \\
93(27.8)\end{array}$} \\
\hline Balloon & Coarctation angioplasty & & & & \\
\hline & Pulmonary angioplasty* & $129(14.9)$ & $22(6.6)$ & $5(1.5)$ & $17(5.1)$ \\
\hline & Aortic valvuloplasty & $90(10.5)$ & $39(11.7)$ & $7(2.1)$ & $32(9.6)$ \\
\hline & Pulmonary valvuloplasty & $84(9.7)$ & $28(8.4)$ & $6(1.8)$ & $22(6.6)$ \\
\hline & Atrial septostomy & $103(12)$ & $55(16.5)$ & $24(7.2)$ & $31(9.3)$ \\
\hline & Other procedures & $14(1.6)$ & 0 & 0 & 0 \\
\hline \multirow{4}{*}{$\begin{array}{l}\text { D e v i c e } \\
\text { occlusion }\end{array}$} & PDA occlusion & $79(9.1)$ & $34(10)$ & $6(1.8)$ & $28(8.3)$ \\
\hline & ASD occlusion & $46(5.3)$ & $7(2.1)$ & $6(1.8)$ & $1(0.3)$ \\
\hline & VSD occlusion & $2(0.2)$ & $3(0.9)$ & $1(0.3)$ & $2(0.6)$ \\
\hline & Other coil occlusions & $11(1.2)$ & $5(1.5)$ & $2(0.6)$ & $3(0.9)$ \\
\hline \multicolumn{2}{|c|}{ Stent implantation/redilatation } & $15(1.7)$ & $8(2.4)$ & $5(1.5)$ & $3(0.9)$ \\
\hline \multirow[t]{3}{*}{$\mathrm{PM} / \mathrm{ICD}$} & Temporary PM & $10(1.1)$ & $5(1.5)$ & $5(1.5)$ & 0 \\
\hline & Permanent Endo PM & $4(0.4)$ & 0 & 0 & 0 \\
\hline & ICD & $1(0.1)$ & 0 & 0 & 0 \\
\hline \multicolumn{2}{|c|}{ Endomyocardial biopsy } & $102(11.8)$ & $6(1.8)$ & $3(0.9)$ & $3(0.9)$ \\
\hline
\end{tabular}

*cutting balloon was used in 3 patients

or intervention related events (including those resulting from the material or its manipulation), related to anesthesia and airway management, infections, allergic reactions and miscellaneous. All cardiac events were considered major events. Major adverse events related to anesthesia were airway and ventilation problems requiring intubation; hypotension and/or bradycardia observed shortly after introduction of the anesthetic drugs and necessitating bag ventilation, intubation or any medication to stabilize the patient. The classification of complications is detailed in Table II.

\section{Cateheterization Technique}

All procedures were done via femoral veins or arteries by a percutaneous technique; except in patients with bilateral cavopulmonary anastamosis; internal jugular veins were used to access the pulmonary arteries. General anesthesia was used only in 54 patients (2\%) during closing of VSD, ASD or stenting the PDA. Others (2574 patients; 98\%) received conscious sedation. Heparin sulphate (100 $\mathrm{IU} / \mathrm{kg}$ ) was administered intravenously after introducing the arterial sheaths. Additional heparin $(50 \mathrm{IU} / \mathrm{kg})$ was given only if the procedure continued for more than one hour. Cineangiography was performed with a low osmolar, non-ionic contrast agent at a dose of $1-2 \mathrm{ml} / \mathrm{kg}$.

\section{Statistical Analysis}

Data were expressed as percentages, medians with ranges, or means with standard deviations. Chi-square analysis or Mann-Whitney $\mathrm{U}$ test was used to examine the differences between groups. Linear regression test was applied to compare risk factors and adverse reactions. Statistical analyses were performed with the SPSS 17.0 program. A p value of less than 0.05 was considered statistically significant.

\section{Results}

Between January 2005 and December 2010, 2662 pediatric cardiac catheterization procedures were performed in 2628 patients. The mean age of patients undergoing cardiac catheterization was $53.2 \pm 64.3$ months (median: 25 months; range 1 day -21 years). Of all the procedures, 1797 were diagnostic $(67.5 \%)$ and 865 were interventional procedures $(32.5 \%)$ Among the interventional procedures, $68.9 \%$ were carried out using a balloon catheter; $15.8 \%$ were device occlusion procedures; $11.9 \%$ were endomyocardial biopsies; $1.7 \%$ were stent implantations, and $1.7 \%$ were pacemaker implantations (Table III).

Vascular access was through a vein in 1334 
Table IV. Distribution of Adverse Events Observed during Pediatric Catheterization Procedures.

\begin{tabular}{lccc}
\hline Event & $\begin{array}{l}\text { Major } \\
\mathrm{n}(\%)\end{array}$ & $\begin{array}{c}\text { Minor } \\
\mathrm{n}(\%)\end{array}$ & $\begin{array}{c}\text { Overall } \\
\mathrm{n}(\%)\end{array}$ \\
\hline Death & $13(1.4)$ & $\mathrm{NA}$ & $13(1.4)$ \\
Cardiac & $35(3.7)$ & $\mathrm{NA}$ & $35(3.7)$ \\
Arrhythmia & $29(3.0)$ & $21(2.3)$ & $50(5.3)$ \\
Vascular complications & $40(4.2)$ & $425(45.2)$ & $465(49.4)$ \\
Catheter/intervention related & $26(2.7)$ & $1(0.1)$ & $27(2.8)$ \\
Anesthesia/airway management related & $56(6.0)$ & $27(2.9)$ & $83(8.9)$ \\
Infections & $14(1.5)$ & 0 & $14(1.5)$ \\
Allergic reactions & $11(1.3)$ & $200(21.2)$ & $211(22.5)$ \\
Miscellaneous & $37(3.9)$ & $6(0.6)$ & $43(4.5)$ \\
\hline Total & $261(27.7)$ & $680(72.3)$ & $941(100)$ \\
\hline
\end{tabular}

(50.8\%), through an artery in $412(15.7 \%)$, and through both vessels in 882 patients $(33.5 \%)$. In $9.8 \%$ of them $(n=257)$ vascular access was obtained percutaneously for monitoring and was not used for catheterization. Time to introduce a sheath to the vessel was $6.7 \pm 8.9$ minutes (range: 1-105 minutes, median 4 minutes). Vascular access was obtained in $\leq 3$ minutes in about half of the cases $(n=1317,49.5 \%)$. On average, total duration of the procedure was 45.4 \pm 23.1 minutes (range 10-200 minutes; median: 40 minutes), and fluoroscopy time was 10.3 \pm 7.9 minutes (range 0.5-150 minutes; median 8.4 minutes). The dose of the contrast material used during the angiography was $2.0 \pm 1.2 \mathrm{ml} / \mathrm{kg}$ (range $0.76-4 \mathrm{ml} / \mathrm{kg}$; median $2.8 \mathrm{ml} / \mathrm{kg}$ ).

A total of 941 adverse events were observed in 688 patients $(26 \%)$. The frequency of minor events was $21.4 \%(n=680)$; major events were only $7.1 \%(n=261)$. The most frequent major complications were anesthesia and airway related complications $(n=56,6 \%)$, whereas most frequent minor complications were vascular complications $(n=425,45.2 \%)$. The distribution of adverse events observed during pediatric cardiac catheterization procedures is given in Table IV.

The patients with major complications were younger (mean age: $20.7 \pm 39$ months), compared to those without complications (mean age: $55.7 \pm 65.2$ months $)(p=0.0001)$. Newborns comprised $32.3 \%$ of patients $(n=341)$ with complications while $7.6 \%(n=71)$ were newborns in patients without complications. Univariate analysis showed that major complications were
2.1 times more frequent during interventional procedures ( $10.6 \%$ major complication during interventions versus $5.5 \%$ during others; $\mathrm{p}=0.0001$, CI:1.5-2.7, OR: 2.1). The mean procedure (60.7 \pm 33.9 minutes) and fluoroscopy times (13.1 \pm 9.5 minutes) were longer in patients with major complications compared to those (mean procedure time $44.2 \pm 21.5$ minutes; mean fluoroscopy time 10.1 1 7.8 minutes) in patients without complications $(p=0.0001)$. Although the mean vascular access time (9.2 \pm 14.1 minutes) was also longer in procedures with major complications (compared to mean access time of $6.5 \pm 8.3$ minutes in patients without complications), this was not statistically significant $(p=0.051)$. All types of major complications were more frequently observed during interventional procedures except for arrhythmias, infections and allergic reactions ( $p>0.05$ for the latter).

Thirteen patients died within 48 hours after cardiac catheterization. Those who died were younger (age of deceased patients: $11 \pm 23$ months, median: 0.8 months; age of patients alive: $60.6 \pm 75.9$ months, median 28 months; $\mathrm{p}=000.1$ ), and had longer procedures (deceased patients: $77.5 \pm 31.8$ minutes, median: 78 minutes; patients alive: $45.2 \pm 22.9$ minutes, median 40 minutes; $\mathrm{p}=000.1$ ). Seven of them $(53.8 \%)$ were critically ill newborns (age: 9 hours - 40 days). They were mechanically ventilated and received inotropic agents before cardiac catheterization. Two patients had balloon atrial septostomy procedures, one patient had balloon coarctation angioplasty and the remaining four had diagnostic procedures. In the older 
Table V. Cardiac Catheterizations Resulted with Death.

\begin{tabular}{|c|c|c|c|c|}
\hline Age & Gender & Diagnosis & Procedure & Cause of death \\
\hline 4 years & M & $\begin{array}{l}\text { BT shunt, dextrocardia, superior- } \\
\text { inferior ventricles, P.atresia, } \\
\text { VSD, ASD }\end{array}$ & Diagnostic & $\begin{array}{l}\text { Desaturation and bradycardia, } \\
\text { resuscitated during catheterization } \\
\text { (shunt stenosis) }\end{array}$ \\
\hline 38 days & $\mathrm{F}$ & $\begin{array}{l}\text { Down syndrome, cAVSD, PDA, } \\
\text { CoA }\end{array}$ & Diagnostic & $\begin{array}{l}\text { Critically ill before catheterization, } \\
\text { death in ICU due to decompensated } \\
\text { CHF }\end{array}$ \\
\hline 40 days & $\mathrm{F}$ & TAPVC (mixed type) & Diagnostic & $\begin{array}{l}\text { Critically ill before catheterization, } \\
\text { death in ICU due to CHF }\end{array}$ \\
\hline 6 years & M & Restrictive CMP & $\begin{array}{l}\text { Endomyocardial } \\
\text { biopsy }\end{array}$ & Cardiac perforation \\
\hline 2 days & $\mathrm{F}$ & TGA, PDA, PFO & $\begin{array}{l}\text { Balloon atrial } \\
\text { septostomy }\end{array}$ & $\begin{array}{l}\text { Critically ill before catheterization, } \\
\text { resuscitated during catheterization, } \\
\text { pneumothorax, death in ICU }\end{array}$ \\
\hline 10 months & $\mathrm{F}$ & $\begin{array}{l}\text { VSD, Patresia, stented PDA } \\
\text { (stent stenosis) }\end{array}$ & $\begin{array}{l}\text { Redilation of } \\
\text { PDA stent }\end{array}$ & Stent occlusion \\
\hline 5 months & M & $\begin{array}{l}\text { Williams syndrome, AS } \\
\text { (supravalvular) }\end{array}$ & Diagnostic & $\begin{array}{l}\text { Myocardial ischemia due to impaired } \\
\text { coronary perfusion }\end{array}$ \\
\hline 25 days & $\mathrm{F}$ & VSD, P.atresia, PDA & Stenting of PDA & Stent migration and occlusion \\
\hline 10 days & M & $\begin{array}{l}\text { DILV, VSD, ASD, P.stenosis, } \\
\text { ASD }\end{array}$ & $\begin{array}{l}\text { Balloon } \\
\text { pulmonary } \\
\text { valvuloplasty }\end{array}$ & $\begin{array}{l}\text { Bradycardia and cardiac arrest during } \\
\text { balloon dilatation }\end{array}$ \\
\hline 8 hours & M & TGA & $\begin{array}{l}\text { Balloon atrial } \\
\text { septostomy }\end{array}$ & $\begin{array}{l}\text { Critically ill before catheterization, } \\
\text { resuscitated during catheterization, } \\
\text { death in ICU }\end{array}$ \\
\hline 9 hours & M & HLHS & Diagnostic & $\begin{array}{l}\text { Critically ill before catheterization } \\
\text { due to } \mathrm{CHF} \text {, death in ICU }\end{array}$ \\
\hline 5 days & $\mathrm{F}$ & TAPVC (infradiaphragmatic) & Diagnostic & $\begin{array}{l}\text { Critically ill before catheterization due } \\
\text { to pulmonary venous hypertension } \\
\text { (obstructive pulmonary venous } \\
\text { return), death in ICU }\end{array}$ \\
\hline 3 days & $\mathrm{F}$ & HLHS, PDA, CoA & $\begin{array}{l}\text { Balloon } \\
\text { coarctation } \\
\text { angioplasty }\end{array}$ & $\begin{array}{l}\text { Critically ill before catheterization } \\
\text { due to } \mathrm{CHF} \text {, death in ICU }\end{array}$ \\
\hline
\end{tabular}

AS: aortic stenosis, ASD: atrial septal defect, BT shunt: Blalock-Taussig,shunt, cAVSD: complete atrioventricular septal defect, CHF: congestive heart failure, CMP: cardiomyopahty, CoA: coarctation of aorta, DILV: double inlet left ventricle, F: female, HLHS: hypoplastic left heart syndrome, ICU: intensive care unit, M: male, Patresia: pulmonary atresia, PFO: patent foravmen ovale, PDA: patent ductus arteriosus, TAPVC: total anomalous pulmonary venous return, TGA: transposition of great arteries, VSD: ventricular septal defect.

patients, three stent related complications (occlusion/stenosis), two myocardial injuries during catheterization (perforation/ischemia) and one during balloon dilatation procedure led to death after catheterization. Details of the deceased patients are given in Table V.

Patients with minor complications were also younger (mean age: 20.5 \pm 48.1 months), than those without complications (mean age: $62.3 \pm 65.3$ months) $(\mathrm{p}=0.0001)$. Risk of having a complicated procedure was 1.5 times more frequent in interventional procedures compared to diagnostic procedures $(\mathrm{p}=0.0001, \mathrm{CI}: 1.2-$ 1.8, OR: 1.5).

All vascular (both minor and major) complications were more frequent among younger patients, especially when the time to access vessel and the duration of the procedure were prolonged $(p<0.0001)$.

When the patients were compared in terms of congenital heart defect and the frequency of complications, cyanotic patients had significantly 
more frequent major and minor complications $(p<0.05$; Odds ratio for major and minor complications: 3.5 and 2 respectively). Patients having obstructive lesions of the ventricular outflow tracts were 2.7 times more likely to have minor complications $(p<0.05$; Odds ratio 2.7 ).

\section{Discussion}

This study revealed that adverse events are more frequently seen in younger patients undergoing prolonged interventional procedures. The risk is amplified if the patient is cyanotic and the vascular access is difficult. Comparison of outcomes with other studies may be difficult due to highly variable case mix, differences in definition of the adverse events, collection of data, and length of the period of observation. Nevertheless, similar to others we observed higher adverse event rates among neonates and infants and in interventional cases. ${ }^{3-6}$

Fortunately, death is not common. Although those that are deceased are younger and have undergone prolonged procedures, death after cardiac catheterization seems to be more associated with the patient's general status than the procedure itself. In pediatric patients, one process is dependent on or linked with the outcomes of prior or succeeding processes. Those who are moribund prior to catheterization will have little chance of survival. ${ }^{3}$ More than half of our patients who died after cardiac catheterization were critically ill newborns. Even diagnostic procedures may be troubling in these patients. In older patients intervention related mortality is more probable. Bergensen L, et al. ${ }^{4}$ reported mortality rate of $0.29 \%$ among 3855 cases from six institutions; seven out of the eleven deceased patients were neonates. Cyanotic patients had increased risk of mortality.

Thirty-day mortality has been used as a marker for quality of health care provided; however it has also been advocated that 30 day mortality does not adequately characterize the quality of outcome in terms of pediatric interventional cardiology. ${ }^{3}$ We did not use 30 day mortality; instead, we considered death as a complication of catheterization if it were seen within 48 hours of the procedure. Even in some of these cases, it was not certain whether death was attributable to the catheterization procedure, to other procedures during the care, or to unrelated patient comorbidities. In the study by Backes $\mathrm{CH}$ et al. ${ }^{3}$, deaths attributed to catheterization were more likely to be in urgent cases. Different studies similarly revealed that deaths were more frequent among the prolonged procedures and interventions, especially during atrial septostomy or balloon interventions. ${ }^{3,7,8}$. Comparably in our study, the adverse event frequency was higher in balloon procedures (overall complication rate $44.7 \%$, major complications $11.9 \%$ ). Then again, they were the most frequent interventions during the study period. While stent implantations were less frequent procedures, overall events (53.3\%) and major adverse event rates (33\%) were significantly high among these patients. As Moore JW et al. ${ }^{8}$, we found out that procedures directed to ASD and PDA were among the safest interventions for congenital heart disease.

In a multicenter prospective study, Bergensen $\mathrm{L}$ et $\mathrm{al}^{2}$ have assigned procedures into risk categories and correlated high risk category groups (like stent implantations to pulmonary arteries and veins, atrial septostomies, balloon procedures in newborn babies etc.) with higher adverse event rates. The type of procedure is definitely consequential in terms of adverse outcomes, but intrinsic patient characteristics, operator skill and experience should also be taken into account. Especially the variables related to the operator are not easily scalable, which creates a major pitfall. ${ }^{9}$

Over the last few decades the congenital catheterization laboratory has evolved to have therapeutic function. Therefore, complication rates of recent studies are slightly higher than those conducted in the 1990's. ${ }^{4,10}$ In single center retrospective studies, major adverse events were previously reported as 0.9-6\%.7, 1113 However, in a multicenter, prospective study by Bergensen $\mathrm{L}$ et $\mathrm{al}^{3}{ }^{3}$, the incidence of major adverse events in interventional cases differed substantially (range: 7-25\%) due to diversity of the case mix among centers. In our study, overall adverse event rate was $26 \%$ and major adverse event rate was $7.1 \%$

Most frequent major complications in our study were anesthesia and airway related complications $(6 \%)$. This is remarkable because general anesthesia was used only in $2 \%$ of all 
cases. This may imply that critically ill patients who are already mechanically ventilated have less airway problems. Therefore, intubating a hemodynamically unstable patient and using general anesthesia instead of conscious sedation may prevent airway related complications in these patients.

Data collection and case entry is the key in prospective studies. The caveat is that, event capture rate tends to be more reliable when the complication is a high severity event, while low severity events may have less reliable reporting. ${ }^{3}$ Dedicated time and commitment is needed to collect complete and accurate data. Larger databases can only be possible if the data collection is faster and the burden of data entry is reduced with improved computerized programming. ${ }^{3}$ Although data collection in our study was prospective and meticulous, the retrospective evaluation of the medical details and self-reporting of the adverse events may have led to bias.

The outcomes of cardiac catheterization procedures in pediatric patients need to be evaluated continuously since there is constant evolution and improvement in these procedures. Defining risk factors will help anticipate adverse events, which will guide in preparation for rescue procedures, organization of catheterization laboratories and improvement of patient safety systems. Patients and families will be provided with more specific counseling and informed consent. Modification of practice to decrease preventable events will definitely contribute to quality improvement acts. ${ }^{5}$ Simple but important precautions like alternative vascular access methods especially in small babies and difficult cases, better anesthetic management by experienced pediatric anesthesiologists, judicious catheter manipulation, stabilizing the patient hemodynamics and correcting any metabolic abnormality beforehand will reduce complications. Using low profile tools and avoiding arterial access whenever possible will avoid vascular injury. Any effort to reduce the procedure time, like studying the case and planning thoroughly before the procedure, will abate most of the adverse outcomes. Defining operator error and establishing guidelines regarding technique and type of material to be used during each intervention will help prevent adverse events.
Our study should be interpreted in the context of several potential limitations. Data are selfreported and self-reporting may lead to possible reporting bias. Late complications occurring after discharge could not be collected. Some low severity events like self-limiting arrhythmias, transient hypotension, metabolic acidosis, stridor, emesis, hypoglycemia might have been underestimated, although a detailed form was filled-out right after the procedure. Assessing outcomes for low frequency procedures may be statistically problematic.

Overall, the complication rates of cardiac catheterization in children are low, but not negligible. The most frequent adverse events in general are vascular complications, whereas events related to anesthesia and airway management seem to be among the most frequent major complications. Cardiac interventions, especially balloon dilatation procedures, catheterizations in cyanotic patients or newborns carry the highest risk. Awareness of complications, improved intensive care, improvement in technique and equipment will decrease or avoid the incidence of complications.

\section{REFERENCES}

1. Mori Y, Nakazawa M, Yagihara T. Complications of pediatric cardiac catheterization and systems of catheterization laboratories minimizing complications-A Japanese multicenter survey. J Cardiol 2010; 56: 183188.

2. Bergensen L, Gauvreau K, Marshall A, et al. Proceduretype risk categories for pediatric and congenital cardiac catheterization. Circ Cardiovasc Interv 2011; 4: 188194.

3. Backes $\mathrm{CH}$, Bergensen L, Rome JJ, et al. Quality metrics in cardiac catheterization for congenital heart disease: Utility of 30-day mortality. Catheter Cardiovasc Interv 2015; 85: 104-110.

4. Bergensen L, Marshall A, Gauvreau K, et al. Adverse event rates in congenital cardiac catheterization-A multicenter experience. Catheter Cardiovasc Interv 2010; 75: 389-400.

5. Lin $\mathrm{CH}$, Hedge $\mathrm{S}$, Marshall $\mathrm{AC}$, et al. Incidence and management of life-threatening adverse events during cardiac catheterization for congenital heart disease. Pediatr Cardiol 2014; 35: 140-148.

6. Jayaram N, Beekman III RH, Benson L, et al. Adjusting for risk associated with pediatric and congenital cardiac catheterization: A report from the NCDR IMPACT registry. Circulation 2015; 132: 1863-1870.

7. Mori Y, Takahashi K, Nakanishi T. Complications of cardiac catheterization in adults and children with congenital heart disease in the current era. Heart Vessels 2013; 28: 352-359. 
8. Moore JW, Vincent RN, Beekman III RH, et al. NCDR IMPACT Steering Committee. Procedural results and safety of common interventional procedures in congenital heart disease: Initial report from the National Cardiovascular Data Registry. J Am Coll Cardiol 2014; 64: 2439-2451.

9. Agnoletti G, Bonnet C, Boudjemline Y, et al. Complications of paediatric interventional catheterisation: An analysis of risk factors. Cardiol Young 2005; 15: 402-408.

10. Bergensen L, Gauvreau K, Jenkins KJ, Lock JE. Adverse event rates in congenital cardiac catheterization: A new understanding of risks. Congenit Heart Dis 2008; 3: 90-105.
11. Cassidy SC, Schmidt KG, Van Hare GF, Stanger P, Teitel DF. Complications of pediatric cardiac catheterization: A 3-year study. J Am Coll Cardiol 1992; 19: 1285-1293.

12. Rhodes JF, Asnes JD, Blaufox AD, Sommer RJ. Impact of low body weight on frequency of pediatric cardiac catheterization complications. Am J Cardiol 2000; 86: 1275-1278, A9.

13.Vitiello R, McCrindle BW, Nykanen D, Freedom RM, Benson LN. Complications associated with pediatric cardiac catheterization. J Am Col Cardiol 1998; 32: 1433-1440. 